\title{
Structural, dielectric, and multiferroic properties of $\left(\mathrm{Bi}_{0.5} \mathrm{~K}_{0.5}\right)\left(\mathrm{Fe}_{0.5} \mathrm{Nb}_{0.5}\right) \mathrm{O}_{3}$ \\ Swagatika Dash, R.N.P. Choudhary, Piyush R. Das, and Ashok Kumar
}

\begin{abstract}
A polycrystalline sample of $\left(\mathrm{Bi}_{0.5} \mathrm{~K}_{0.5}\right)\left(\mathrm{Fe}_{0.5} \mathrm{Nb}_{0.5}\right) \mathrm{O}_{3}$ was prepared using a mixed oxide at $1000{ }^{\circ} \mathrm{C}$. The preliminary structural analysis using X-ray diffraction data of the compound indicates the formation of a single-phase rhombohedral structure similar to that of parent $\mathrm{BiFeO}_{3}$. Microstructural and elemental analysis using a scanning electron micrograph and energy-dispersive X-ray spectroscopy, respectively, were carried out at room temperature with higher magnification exhibiting a uniform distribution of grains and stoichiometry. The appearance of hysteresis loops $(P-E)$ confirms the existence of ferroelectricity of the sample with a high remnant polarization of $\left(2 P_{\mathrm{r}}\right) 17.76 \mu \mathrm{Ccm}^{-2}$. Using impedance spectroscopy, the electrical properties of the material were investigated at a wide range of temperature $\left(25-500{ }^{\circ} \mathrm{C}\right)$ and frequencies $(1 \mathrm{kHz}-1 \mathrm{MHz})$ suggesting dielectric non-Debye-type relaxation in the material. The nature of the Nyquist plot $\left(Z^{\prime} \sim Z^{\prime \prime}\right)$ shows the dominance of the grain contribution in the impedance. The bulk resistance of the compound decreases with increasing temperature, like that of a semiconductor, which shows a negative temperature coefficient of resistance (NTCR) behavior. The frequency dependence of AC conductivity suggests that that the material obeys Jonscher's power law. Magnetic hysteresis $(M-H)$ loop shows very weak ferromagnetic behavior at room temperature.
\end{abstract}

PACS Nos.: 75.85+t, 61.10.Nz, 77.22.-d, 72.80.Le.

Résumé : Nous préparons un échantillon poly-cristallin de $\left(\mathrm{Bi}_{0.5} \mathrm{~K}_{0.5}\right)\left(\mathrm{Fe}_{0.5} \mathrm{Nb}_{0.5}\right) \mathrm{O}_{3}$ par mélange d'oxydes à $1000{ }^{\circ} \mathrm{C}$. L'analyse préliminaire de structure à l'aide de la diffraction $\mathrm{X}$ indique la formation d'une structure rhomboèdre à phase unique, similaire à celle du parent $\mathrm{BiFeO}_{3}$. L'analyse micro-structurelle et fondamentale utilisant les techniques SEM et EDAX de micrographie électronique à balayage, à la température de la pièce et plus haute magnification, montre une distribution uniforme des grains et de la stœchiométrie. L'apparition de boucles d'hystérèse $(P-E)$ confirme la ferroélectricité de l'échantillon avec une haute polarisation rémanente de $\left(2 P_{\mathrm{r}}\right) 17.76 \mu \mathrm{Ccm}^{-2}$. L'utilisation d'une technique de spectroscopie d'impédance permet une étude des propriétés électriques de l'échantillon, sur de larges domaines de température $\left(25-500{ }^{\circ} \mathrm{C}\right)$ et de fréquence $(1 \mathrm{kHz}-1 \mathrm{MHz})$, qui suggère une relaxation diélectrique dans le matériel qui n'est pas du type Debye. Le graphique $\left(Z^{\prime} \sim Z^{\prime \prime}\right)$ de Nyquist montre la dominance de la domination du grain dans l'impédance. La résistance en volume de l'échantillon décroit lorsqu'augmente la température, de façon similaire à un semi-conducteur avec un coefficient thermique de résistance négatif. La dépendance en fréquence de la conductivité ac suggère que le matériel obéit à une loi de puissance de Joncher. La boucle d'hystérèse ( $M-H)$ est caractéristique d'un très faible ferromagnétisme à la température de la pièce. [Traduit par le Rédaction]

\section{Introduction}

Multiferroics exhibit multiple ferroic properties (i.e., ferroelectricity and ferromagnetism in a structurally distorted system), which allow mutual control of electric polarization with magnetic field or controlling magnetization by electric field. This phenomenon is generally known as magnetoelectric effect. Magnetoelectric effects make them potential cadidates for fabrication of devices: spintronics, memory, sensors, oscillators, phase shifters, etc. [1-5]. Among the multiferroics developed today, $\mathrm{BiFeO}_{3}(\mathrm{BFO})$ has received tremendous attention over the last few years because of its unique ferroelectric $\left(T_{c}=1100 \mathrm{~K}\right)$ as well as magnetic $\left(T_{\mathrm{N}}=\right.$ $650 \mathrm{~K})$ properties $[6,7]$. The high transition temperatures of the material have made it more useful and meaningful for the fabrication of devices. It has a rhombohedrally distorted perovskite structure with space group R3c [8, 9]. However, the high-leakage current or tangent loss of BFO limits its applications. The lowresistivity of BFO is caused by the valence fluctuation of Fe ions and existence of secondary phases. Recently, a large polarization was reported in thin films of the compound [10]. But in bulk ceramics, because of defect and non-stoichometry, the polariza- tion is very low, which also limits its applications. BFO is antiferromagnetic with a very small residual magnetic moment [11]. To improve the multiferroic properties of $\mathrm{BiFeO}_{3}$, various attempts have been made, including substitution of suitable elements and rare earth metals ( $\mathrm{Tb}, \mathrm{Nd}, \mathrm{Sm}, \mathrm{Gd})$ at the Bi site or fabrication of solid-solution-composites with another ferrites, ferroelectric and (or) polymers [12-15]. In this process, magnetization was found to be enhanced on substitution of $\mathrm{Y}$ at the Bi site [16]. Solid solutions of $\mathrm{BFO}$ fabricated with other $\mathrm{ABO}_{3}$-type perovskites improve the dielectric and magnetic properties with structural stability. The solid solution of $\mathrm{BFO}$ with $\mathrm{BaTiO}_{3}$ showed much improved dielectric properties, and hence the crystal structure of BFO was stabilized by removing impurity phases [17]. Magnetic properties of the materials were enhanced on addition of $\mathrm{DyFeO}_{3}$ to $\mathrm{BFO}[18]$. An enhancement in remnant polarization and magnetization was observed when $\left(\mathrm{Bi}_{0.5} \mathrm{Na}_{0.5}\right) \mathrm{TiO}_{3}$ was added to $\mathrm{BFO}$ [19]. The solid solution of $\mathrm{BFO}-\mathrm{NaNbO}_{3}$ has enhanced ferroelectric properties with reduction in leakage current [20]. However, not much improvement in the ferroelectric and magnetic properties in the solid solution of $\mathrm{BFO}-\mathrm{KNbO}_{3}$ was observed [21].

Received 13 January 2014. Accepted 6 November 2014.

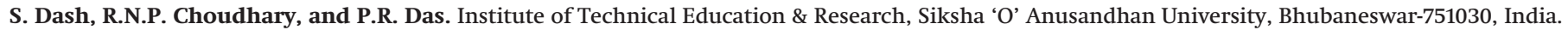
A. Kumar. National Physical Laboratory, Delhi-110012, India.

Corresponding author: Swagatika Dash (e-mail: swagality@gmail.com). 
An improvement in the dielectric properties of $\mathrm{BFO}$ was observed on addition of $\mathrm{LiNbO}_{3}$ to the compound [22]. As $\mathrm{KNbO}_{3}$ has high spontaneous polarization of $0.41 \mathrm{C} / \mathrm{cm}^{2}$ [23], it is expected to improve the ferroelectric properties of BFO. In view of this, we have synthesized a solid solution of $\mathrm{BFO}$ and $\mathrm{KNbO}_{3}$ in equal molar ratio and studied its structural, microstructural, electrical, ferroelectric, and magnetic properties.

\section{Experimental procedure}

The polycrystalline sample of $\left(\mathrm{Bi}_{0.5} \mathrm{~K}_{0.5}\right)\left(\mathrm{Fe}_{0.5} \mathrm{Nb}_{0.5}\right) \mathrm{O}_{3}$ (or BKFN) was prepared through conventional means using a standard hightemperature solid-state reaction with high-purity $(99.9 \%$ pure or AR grade) ingredients; $\mathrm{Bi}_{2} \mathrm{O}_{3}, \mathrm{~K}_{2} \mathrm{CO}_{3}, \mathrm{Fe}_{2} \mathrm{O}_{3}$, and $\mathrm{Nb}_{2} \mathrm{O}_{5}$ (M/S Loba Chemie, Pvt. Ltd. India). The fine powders of these starting compounds were weighed in proper stiochiometry, and then mixed thoroughly in dry and then in wet medium (methanol) for $3 \mathrm{~h}$ in an agate mortar. Then the resultant mixture was calcined at $1000{ }^{\circ} \mathrm{C}$ for $8 \mathrm{~h}$. The formation of the compound BKFN was checked using X-ray diffraction at room temperature with an X-ray diffractometer (Bruker Advanced D8) using $\mathrm{CuK} \alpha$ radiation $(1.5405 \AA)$ over a wide range of Bragg angles $\left(20^{\circ}<2 \theta<80^{\circ}\right)$ with a scanning rate of $2^{\circ} / \mathrm{min}$. After calcination, the powder was then mixed with a binder polyvinyl alcohol (PVA). Pellets of diameter $10 \mathrm{~mm}$ and thickness $1-2 \mathrm{~mm}$ were fabricated using a hydraulic press. The pellets were then sintered at $1050{ }^{\circ} \mathrm{C}$ for $6 \mathrm{~h}$. The microstructure of the pellet was recorded using a scanning electron microscope (JEOL JSM-5800). For electrical measurements, silver paste was coated on both the surfaces of the disc, which act as electrodes. In the present investigation, the dielectric and electrical measurements was carried out using a PSM 1735:N4L impedance analyzer with indigenously developed two-terminal sample holders in the frequency range of $1 \mathrm{kHz}-1 \mathrm{MHz}$. The offset voltage given to the sample is $1 \mathrm{~V}$. The polarization (hysteresis loop) of the sample at various fields was obtained using a hysteresis loop tracer (Version 4.9.0 of Radiant Technologies, Inc., 1999-10/02/12). The current density - electric field characteristic of the sample was measured at different temperatures by an electrometer (Keithley Instruments Inc. model 6517B). The magnetic measurement was carried out using a superconducting quantum interference device magnetometer (Ever Cool SQUID VSM DC magnetometer) at room temperature.

\section{Results and discussion}

\subsection{Structural and microstructural properties}

Figure 1 shows the room temperature X-ray diffraction pattern of BKFN. The nature of the pattern (peaks' positions and their intensities) confirms the formation of a single-phase compound similar to BFO. However, some small peaks (not related to BFO) appeared (indicated with asterisks) that may be related to secondary phase $\mathrm{Bi}_{2} \mathrm{O}_{3}$. All the peaks (except the impurity phase) were indexed using a computer program POWD [24]. Preliminary structural analysis shows that the material is crystallized to rhombohedral (hexagonal), as that of the parent (BFO). The obtained lattice parameters were refined using the least-squares method. The refined lattice parameters are: $a=5.6473$ (28) $\AA, c=13.867$ (28) $\AA$ (the standard deviations are noted in parenthesis). The average crystallite size of the sample was calculated from X-ray line broadening using Scherrer's equation [25],

$D=\frac{K \lambda}{\beta_{1 / 2} \cos \theta_{h k l}}$

where $K$ is a constant equal to $0.89, \lambda=1.5405 \AA, \beta_{1 / 2}$ is the full width at half maximum (rad), and $\theta_{h k l}$ is the Bragg angle. The average value of crystallite size is found to be $33.6 \mathrm{~nm}$.
Fig. 1. X-ray diffraction pattern of BKFN for $x=0.5$ at room temperature.

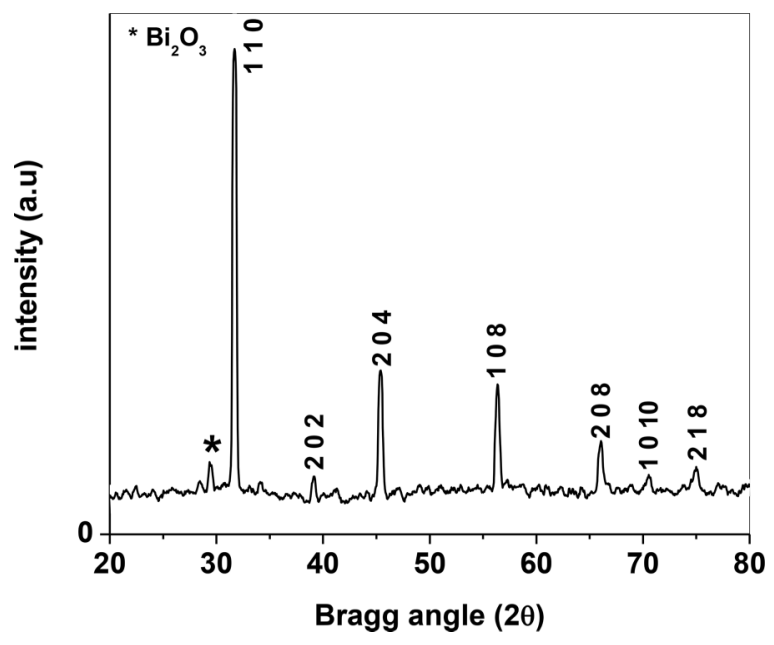

Figure $2 a$ shows the scanning electron microscope image of BKFN recorded at room temperature, which reveals that the grains are of varying size, but have well-defined and sharp edges. The grains are evenly distributed over the surface. Figure $2 b$ shows the compositional analysis of the sample using energy-dispersive X-ray spectroscopy (EDAX). All the peaks of the EDAX pattern have been perfectly assigned to the elements present in BKFN, which shows that there is a good agreement between theoretical calculation and experimental result of the elements in the sample. The compositions are found to be $42.52 \%, 7.74 \%, 10.74 \%, 19.67 \%$, and $19.34 \%$ whereas the theoretical values are $42.40 \%, 7.93 \%, 11.33 \%$, $18.85 \%$, and $19.47 \%$ for $\mathrm{Bi}, \mathrm{K}, \mathrm{Fe}, \mathrm{Nb}$, and $\mathrm{O}$, respectively. This clearly indicates the purity and formation of BKFN.

\subsection{Dielectric properties}

Figure 3 shows frequency dependence of relative dielectric constant $\left(\epsilon_{\mathrm{r}}\right)$ at various temperatures. It is observed that $\epsilon_{\mathrm{r}}$ decreases rapidly with increasing frequency and becomes independent at higher frequencies. The decrement is attributed to the dielectric relaxation. This is very much consistent with that of nonlinear dielectrics because at lower frequencies all the polarizations (i.e., interfacial, dipole, ionic, atomic, and electronic) are present in the samples. When an external field is applied, the dipoles take some time to align themselves in the direction of the field and that time is called relaxation time, which is nearly equal to $10^{-9} \mathrm{~s}$ [26]. As frequency increases, a point is reached where the charge carriers do not align with the field, and as a result, polarization does not reach saturation. As the dipoles begin to lag behind the field, the dielectric constant decreases. At very high frequencies, the dipoles can no longer follow the field, and hence remain constant. The decrease in relative dielectric constant can also be explained based on the hopping of electrons from $\mathrm{Fe}^{2+}$ to $\mathrm{Fe}^{3+}$ ions, because the electrons require a large amount of energy. At low frequency, the electron does not get enough energy for hopping but at higher frequencies; they acquire sufficient energy, and hence hopping takes place between $\mathrm{Fe}^{2+}$ and $\mathrm{Fe}^{3+}$. Therefore, conductivity increases and the dielectric constant decreases [26].

Figure 4 shows temperature dependence of relative dielectric constant $\left(\epsilon_{\mathrm{r}}\right)$ and tangent loss $(\tan \delta)$ for BKFN at selected frequencies $(10 \mathrm{kHz}, 100 \mathrm{kHz}$, and $1 \mathrm{MHz})$. The value of $\epsilon_{\mathrm{r}}$ is almost frequency independent for small temperatures $\left(200{ }^{\circ} \mathrm{C}\right)$. Above $200{ }^{\circ} \mathrm{C}$, it induces strong frequency as well as temperature dependent parameters. It is found that $\epsilon_{\mathrm{r}}$ increases with increasing temperature. The nature of variation of $\tan \delta$ with temperature is same as that of $\epsilon_{\mathrm{r}}$. Generally, $\tan \delta$ has a very high value in the 
Fig. 2. (a) Scanning electron microscope micrograph of BKFN; (b) EDAX spectra of BKFN.

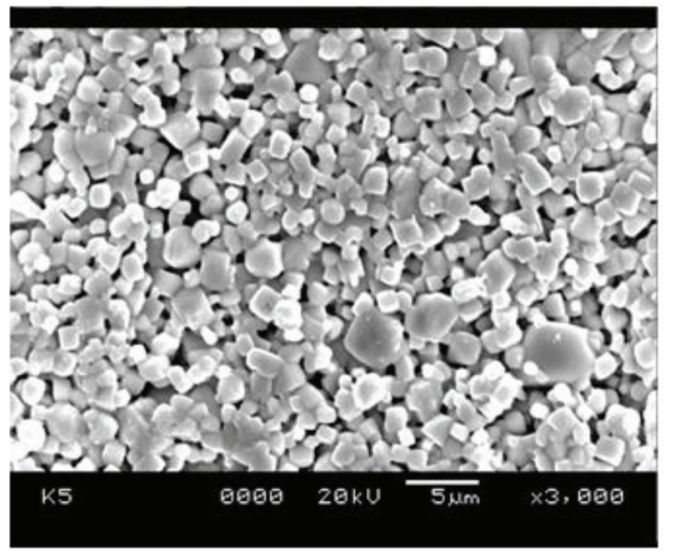

(a)

Fig. 3. Dielectric constant with frequency of BKFN for various temperatures.

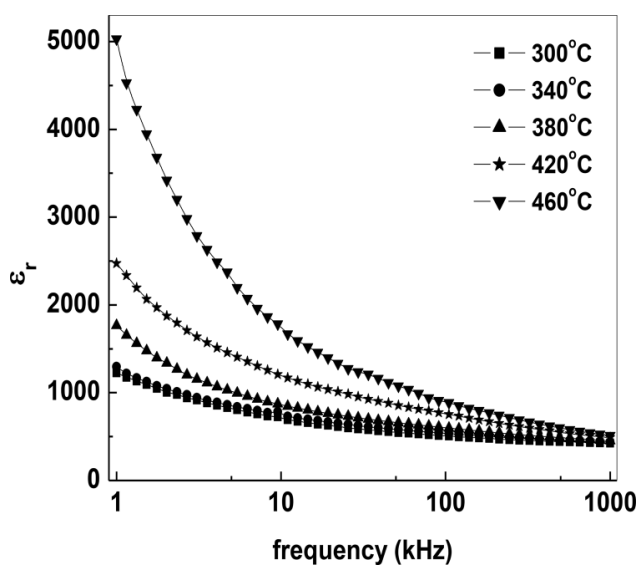

low-frequency region and at high temperatures, in Fe-containing compounds, which decreases rapidly at higher frequencies. No dielectric anomaly or phase transition is observed in a wide temperature range $\left(25-500{ }^{\circ} \mathrm{C}\right)$. The increase in the value of $\tan \delta$ might be due to increased electrical conductivity. A hump is seen around $370{ }^{\circ} \mathrm{C}$, which may be related to some thermal processes occurring in the material signifying energy loss. However, the peak is frequency dependent, and is suppressed at high frequency, which may be because of the possibility of space charge relaxation. In the ceramic sample of the material, the ionic conductivity is due to the movement of alkali ions. Because $\mathrm{K}^{+}$ions move easily on heating, as a result, conductivity increases, and hence $\tan \delta$ increases with temperature.

\subsection{Polarization study}

Figure 5 shows electrical polarization - electric field $(P-E)$ hysteresis loops of BKFN measured at various electric fields at room temperature at $20 \mathrm{~Hz}$. The appearance of loops confirms that the material is ferroelectric. It is found that the values of polarization $\left(P_{\mathrm{r}}\right)$ and coercive fields $\left(E_{\mathrm{C}}\right)$ increase with increasing electric fields. The value of remnant polarization $\left(2 P_{r}\right)$ and coercive field $\left(2 E_{C}\right)$ measured at a voltage of $4 \mathrm{kV}$ are found to be $17.76 \mu \mathrm{Ccm}^{-2}$ and $36.58 \mathrm{kV} / \mathrm{cm}$, respectively.

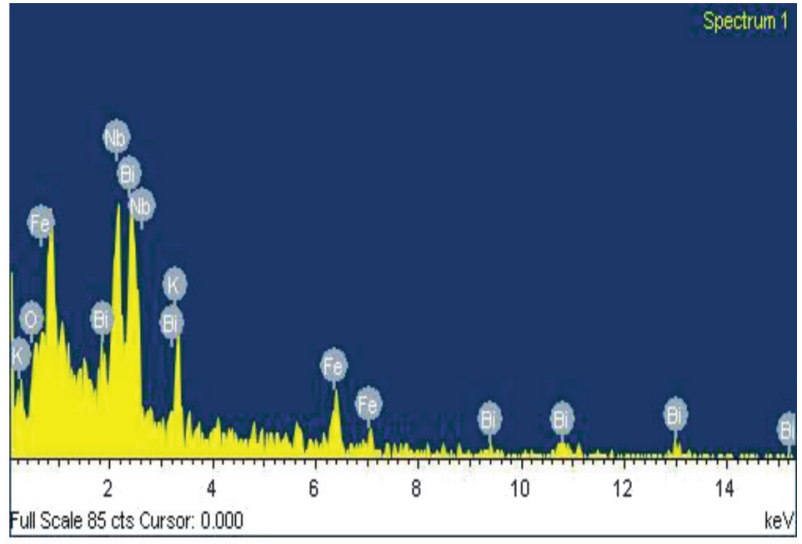

(b)

Fig. 4. Dielectric constant and dielectric loss with temperature of BKFN for various frequencies $(10 \mathrm{kHz}, 100 \mathrm{kHz}$, and $1 \mathrm{MHz})$.

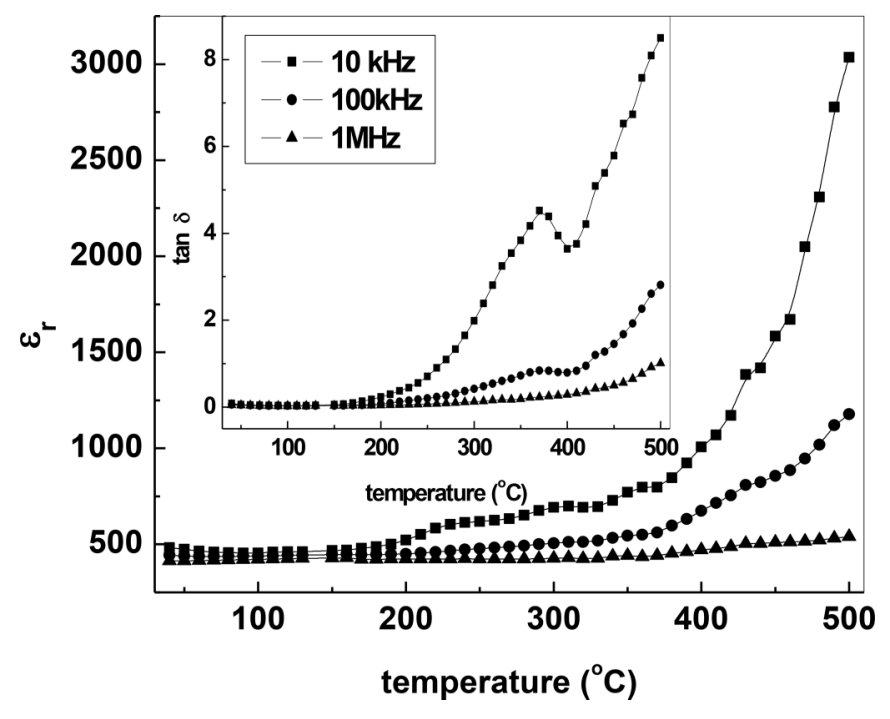

3.4. Complex impedance analysis

The complex impedance spectroscopy is a powerful tool for electrical characterization of materials over a wide range of temperature and frequency. This technique is also used to investigate the dynamics of bound or mobile charge carriers in dielectrics. The electrical properties are represented in terms of complex parameters as

Complex permittivity $\quad \epsilon^{*}(\omega)=\epsilon^{\prime}-j \epsilon^{\prime \prime}$

Complex impedance

$$
Z^{*}(\omega)=Z^{\prime}-j Z^{\prime \prime}=\frac{1}{j \omega C_{0} \epsilon^{*}}
$$

Complex modulus

$$
\begin{aligned}
M^{*}(\omega)=M^{\prime}+j M^{\prime \prime}=\frac{1}{\epsilon^{*}}= & j \omega \epsilon_{0} Z^{*} \\
& =j \omega \epsilon_{0} \frac{1}{Y^{*}}
\end{aligned}
$$

Complex admittance

$$
Y^{*}(\omega)=Y^{\prime}+j Y^{\prime \prime}=j \omega C_{0} \epsilon^{*}
$$


Fig. 5. P-E hysteresis loop for various fields at room temperature of BKFN.

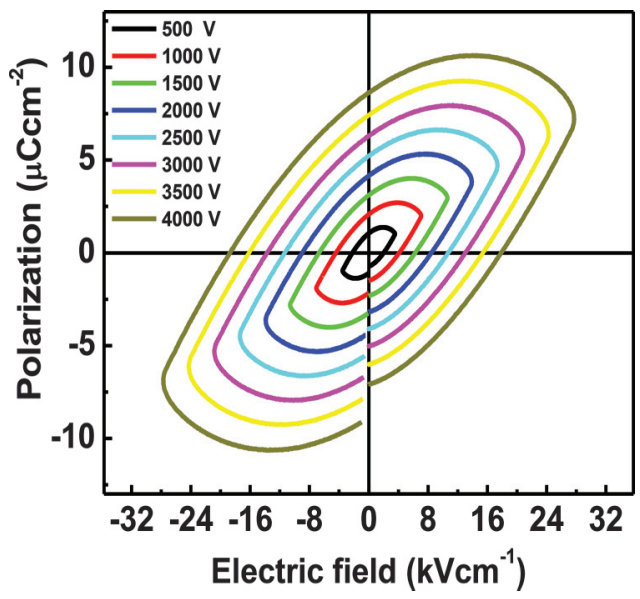

$\tan \delta=\frac{\epsilon^{\prime \prime}}{\epsilon^{\prime}}=\frac{M^{\prime \prime}}{M^{\prime}}=\frac{Z^{\prime}}{Z^{\prime \prime}}=\frac{Y^{\prime}}{Y^{\prime \prime}}$

where $\omega=2 \pi f$ is the angular frequency; $C_{0}=\epsilon_{0} A / d$ is the geometrical capacitance; $\epsilon_{0}$ is the permittivity of free space; $d$ and $A$ are the thickness and area of the sample, respectively; and $j=\sqrt{-1}$ is the imaginary factor.

Figure 6 shows the frequency dependence of real $\left(Z^{\prime}\right)$ and imaginary $\left(Z^{\prime \prime}\right)$ components of impedance at various temperatures. It is observed that $Z^{\prime}$ decreases with increasing frequency as well as temperature, indicating an increase in AC conductivity. The values of $Z^{\prime}$ for all temperatures merge at higher frequencies indicating temperature- and frequency-independent behavior of the material in said frequency range. This is due to the release of space charge, and reduction in barrier properties of the material with rise in temperature $[27,28]$. The larger values of $Z^{\prime}$ at low frequencies indicate larger effects of polarization. At low frequency, the value of $Z^{\prime}$ decreases with increasing temperature showing negative temperature coefficient of resistance type of behavior similar to that of semiconductors.

The value of $Z^{\prime \prime}$ reaches a maximum peak $\left(Z_{\max }^{\prime \prime}\right)$ called relaxation frequency. On increasing temperature these peaks shift towards the higher frequency side, which indicates the existence of more than one relaxation phenomenon in the material. The asymmetric broadening of the peak suggests spreading of relaxation with temperature. This indicates that relaxation in the material is temperature dependent [29]. The value of $Z_{\max }^{\prime \prime}$ decreases with increasing temperature, indicating a decrease in the bulk resistance. The merging of the value of $Z^{\prime \prime}$ in the high-frequency range may be due to accumulation of space charge in the material [30, 31]. The relaxation time can be calculated from maximum frequency $\left(f_{\max }\right)$ at $Z_{\max }^{\prime \prime}$. The peak relaxation frequency is defined as $\omega_{\mathrm{m}} \tau_{\mathrm{m}}=2 \pi f_{\max } \tau_{\mathrm{m}}=1$, where $\tau_{\mathrm{m}}$ is the relaxation time and $\omega_{\mathrm{m}}$ is the relaxation frequency.

Figure $7 a$ shows temperature dependence of complex impedance spectra over a wide range of frequencies $(1 \mathrm{kHz}-1 \mathrm{MHz})$. For an ideal Debye-type relaxation, a perfect semicircle with its centre lying on the $Z^{\prime}$ axis is observed. The figure shows depressed semicircles that have their centers below the $Z^{\prime}$ axis, which indicates deviation from ideal Debye behavior [32]. It also shows that instead of a single relaxation time, there is a distribution of relaxation time, which is temperature dependent [33, 34]. It indicates that a thermally activated process of hopping-type mechanism of the charge carrier dominates [35]. The inset in the figure shows a
Fig. 6. $Z^{\prime}$ and $Z^{\prime \prime}$ with frequency of BKFN at different temperatures.

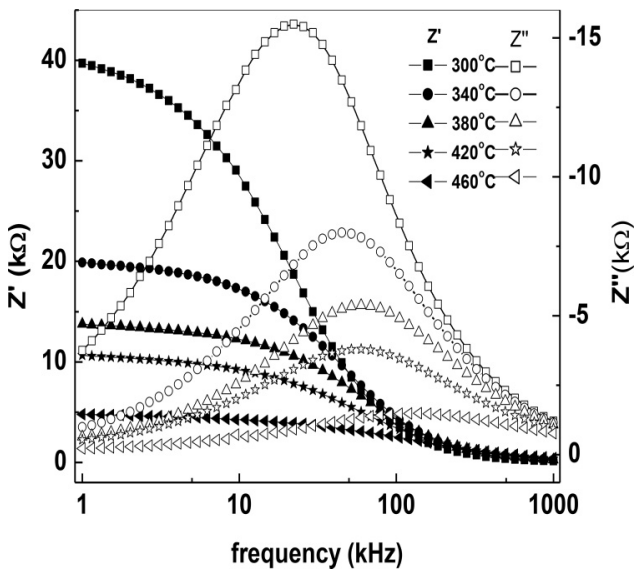

Nyquist plot at low temperatures $\left(100,140,180,220\right.$, and $\left.260^{\circ} \mathrm{C}\right)$. A single semicircle is seen up to $380^{\circ} \mathrm{C}$, but above that temperature, there is a tendency to form a second semicircle in the lowfrequency range. The first semicircle of the high-frequency region is the one because of resistance within the grains of the material, and other due to partial or complete blocking of charge carriers at grain boundaries. It shows that the impedance contribution is mainly due to grains, whereas the grain boundary has a less significant contribution to impedance. The intercepts of each semicircle on the $Z^{\prime}$ axis give the contribution of grain $\left(R_{g}\right)$ and grain boundary resistances $\left(R_{\mathrm{gb}}\right)$. It is observed that these depressed semicircles correspond to a parallel combination of resistance and capacitance. The angle at which the semicircle is depressed below the real axis is related to the width of the relaxation time distribution and is termed constant phase element. When temperature increases, these semicircles become smaller and shift towards lower $Z^{\prime}$ values, indicating a reduction in grain and grain boundary resistances with temperature. Using the computer program Zswimpwin, the fitted complex plots of the sample, along with the equivalent circuit model (shown in Fig. $7 b$ ) has been shown in Fig. 7a. To represent non-Debye behavior, constant phase element is introduced with resistors and capacitors [36].

The relaxation time $(\tau)$ was calculated using the relation; $\tau=R_{\mathrm{b}} C_{\mathrm{b}}$ where $R_{\mathrm{b}}$ and $C_{\mathrm{b}}$ are the bulk resistance and capacitance, respectively. Relaxation time is independent of the geometrical factors, but depends on intrinsic properties of the sample.

Figure 8 shows variation of relaxation time with the inverse of temperature. It is observed that the value of $\tau$ decreases with rise in temperature; a typical semiconductor behavior. The activation energies of the sample are calculated from the Arrhenius relation, $\tau=\tau_{0} \exp \left(-E_{\mathrm{a}} / K T\right)$, where $\tau_{0}$ is the pre-exponential factor, $K$ is the Boltzmann constant, and $\mathrm{T}$ is the absolute temperature. The activation energy of the sample was calculated using linear squares fit to the data points for the low and high temperature regions separately from the slopes of $\log \tau$ versus $1000 / T$. The value of $E_{\mathrm{a}}$ is found to be 0.66 and $0.81 \mathrm{eV}$ in the temperature regions of 240$380{ }^{\circ} \mathrm{C}$ and $400-480{ }^{\circ} \mathrm{C}$, respectively.

\subsection{Electrical conductivity}

\subsubsection{AC conductivity}

Figure 9 shows the variation of AC conductivity $\left(\sigma_{\text {ac }}\right)$ with frequency at selected temperatures. The value of $\sigma_{\mathrm{ac}}$ is calculated using the formula, $\sigma_{\mathrm{ac}}=\epsilon_{\mathrm{o}} \epsilon_{\mathrm{r}} \omega \tan \delta$, where $\epsilon_{\mathrm{o}}$ is the permittivity of free space, $\epsilon_{\mathrm{r}}$ is the relative permittivity, $\omega$ is the angular frequency, and $\tan \delta$ is the dielectric loss. In the low-frequency region, the value of $\sigma_{\mathrm{ac}}$ is almost constant, whereas in the highfrequency region dispersion in the conductivity is observed. An 
Fig. 7. (a) $Z^{\prime}$ with $Z^{\prime \prime}$ BKFN ceramics at different temperatures. Inset: $Z^{\prime}$ with $Z^{\prime \prime}$ BKFN ceramics at low temperatures. (b) Equivalent circuit of BKFN ceramic.

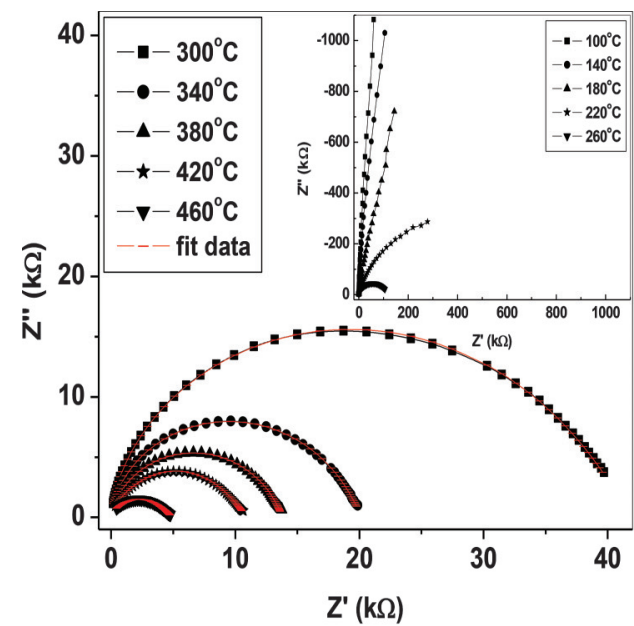

(a)

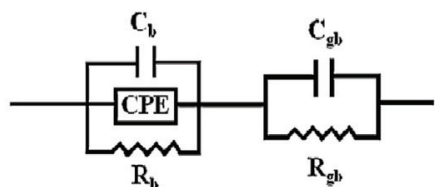

(b)
Fig. 8. Relaxation time with inverse temperature of BKFN.

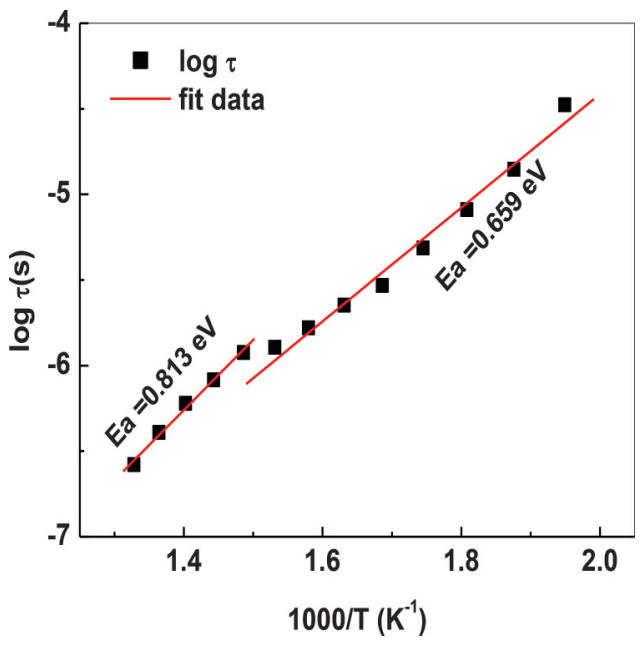

extrapolation of the curve towards lower frequencies gives a value of $\sigma_{\mathrm{dc}}$. It shows that there is conductivity relaxation that indicates transition from long-range to short-range charge carrier. At low frequency, the conductivity is due to hopping of ions between the $\mathrm{A}$ and $\mathrm{B}$ sites, which are restricted to the high-frequency region. The frequency at which change in slope takes place is known as hopping frequency, which depends on temperature. The phenomenon of AC conductivity dispersion in the material is analyzed by Jonscher's power law [30].

$\sigma_{\mathrm{ac}}=\sigma_{\mathrm{dc}}+A_{\mathrm{T}} \omega^{n}$

where $\sigma_{\mathrm{dc}}$ is frequency-independent conductivity (related to DC conductivity), $A_{\mathrm{T}}$ is the pre-exponential factor dependent on temperature, and $n$ is the exponent and can have values between 0 and 1 . If the value of $n<1$ then it indicates that the hopping motion is translational and if $n>1$ the motion involves hopping in localized jumps without leaving the neighborhood. It is found that the material obeys a universal power law, which is confirmed by a typical nonlinear fit of (6) to the experimental data, from
Fig. 9. AC conductivity with frequency at various temperatures of BKFN.

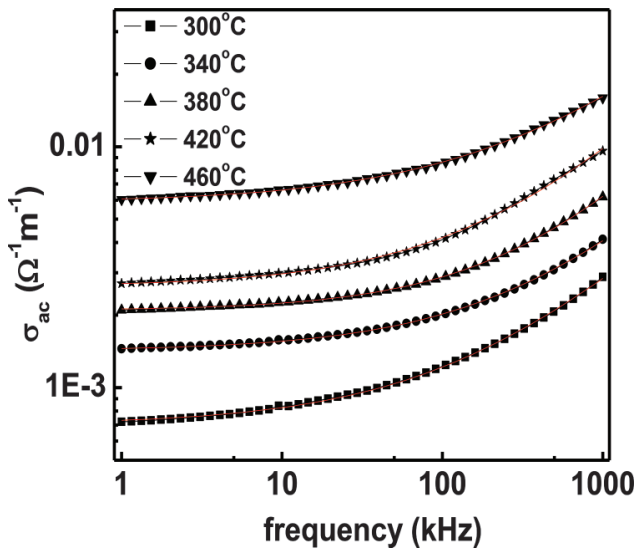

which it is found that $n<1$, indicating that the motion of the charge carriers is translational [37].

Figure 10 shows the variation of $\sigma_{\mathrm{ac}}$ with inverse of absolute temperature at different frequencies $(10 \mathrm{kHz}, 100 \mathrm{kHz}$, and $1 \mathrm{MHz})$. The value of $\sigma_{\mathrm{ac}}$ increases with rising temperature. The increase in conductivity is due to the hopping action of electrons between $\mathrm{Fe}^{2+}$ and $\mathrm{Fe}^{3+}$ ions at high temperatures. The activation energy, $E_{\mathrm{a}}$, which is dependent on thermal activated process, can be calculated using the relation

$\sigma_{\mathrm{ac}}=\sigma_{0} \exp \left(-\frac{E_{\mathrm{a}}}{K T}\right)$

where $\sigma_{0}$ is the pre-exponential factor, and $K$ is the Boltzmann constant. For each frequency plot different slopes in the low- and high-temperature regions suggest the presence of different types of conduction processes with different activation energies. The low activation energy in the low-temperature region suggests the contribution of space charges. It is seen that at high temperature and low frequency the value of $\sigma_{\mathrm{ac}}$ is very high compared to that in the low-temperature region. This is because at low frequencies the conductivity is due to the mobility of charge carriers over long 
Fig. 10. AC conductivity with inverse temperature at various frequencies of BKFN.

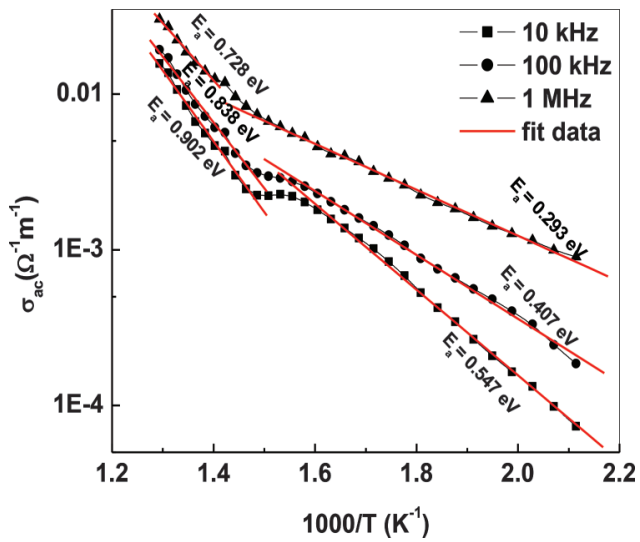

distances rather than from relaxation or orientation mechanism in which the charge mobility is restricted to only the nearest neighboring lattice sites. The value of activation energy for AC conductivity is found to increase with increasing temperature. It is found that at high temperatures $\sigma_{\mathrm{ac}}$ for all frequencies nearly tend to merge, which indicates frequency-independent behavior in that region. The charge carriers responsible for the electrical conductivity at high temperatures are mainly due to the thermally activated oxygen vacancies (doubly ionized).

\subsubsection{DC conductivity}

The DC electrical conductivity of the sample is calculated using the expression, $\sigma_{\mathrm{dc}}=t / A R$, where $R$ may be $R_{\mathrm{b}}$ (bulk resistance) or $R_{\mathrm{gb}}$ (grain boundary resistance); and $t$ and $A$ are the thickness and area of the sample, respectively. Figure 11 shows the variation of DC conductivity with inverse of absolute temperature. The increasing nature of conductivity with temperature supports negative temperature coefficient of resistance behavior of the sample. The nature of plot follows the Arrhenius relation,

$\sigma_{\mathrm{dc}}=\sigma_{0} \exp \left(\frac{-E_{\mathrm{a}}}{K T}\right)$

The slope of the plots gives an activation energy that is nearly $0.539 \mathrm{eV}$ for bulk and $1.57 \mathrm{eV}$ for grain boundary. The plot suggests the possibility of electrical conduction due to mobility of oxide ion vacancies at high temperatures. The values of activation energies are different from the values that have been calculated from relaxation time plot. This implies that the charge carriers responsible for conduction and relaxation are different.

\subsection{J-E characteristics}

Figure 12 shows the semi-log plot of current density $(J)$ with electric field $(E)$ at a few selected temperatures (room temperature $\left(30^{\circ} \mathrm{C}\right), 100,150,200,250,300$, and $350{ }^{\circ} \mathrm{C}$ ). The value of $J$ slowly increases with rising electric field. In the low-field region (up to $200 \mathrm{kV} / \mathrm{cm}$ ) of the $J-E$ characteristic plot, the slope is nearly equal to one, which indicates that the current conduction is of Ohmic type. In the high-field region, the slope is greater than one indicating the presence of space charge limited current conduction.

\section{7. $M-H$ loop}

Figure 13 shows the magnetic hysteresis loop of the sample. Superimposed on anti-ferromagnetic ordering, there is a spiral spin structure because of which the magnetization in BFO vanishes [38]. The suppression of these spiral spin structures causes a weak ferromagnetism in the material. There is a weak ferromagnetism
Fig. 11. DC conductivity with inverse temperature of BKFN.

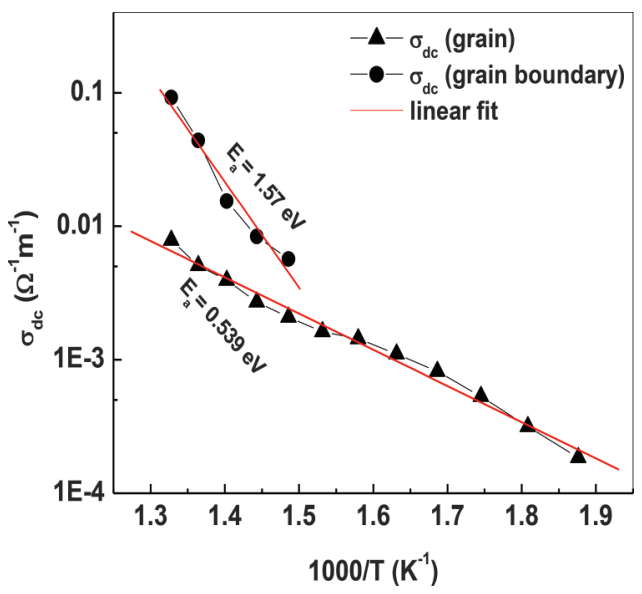

Fig. 12. Logarithmic plots of $J$ as a function of $E$ of BKFN.

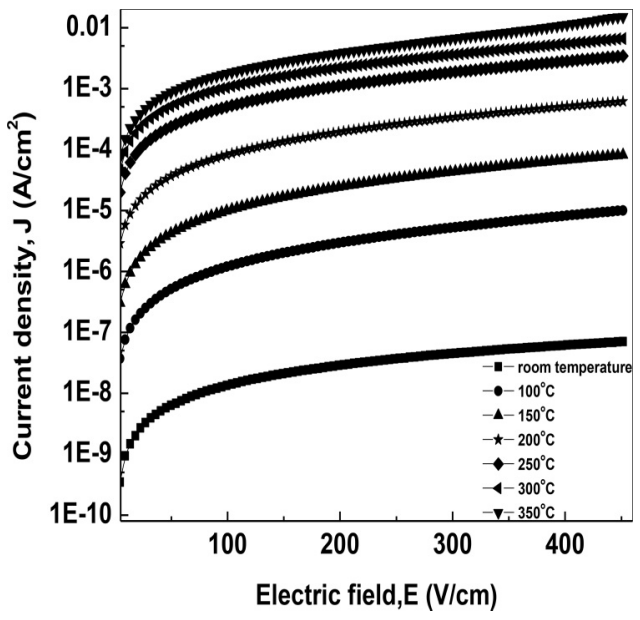

Fig. 13. Magnetic hysteresis loop of BKFN at $300 \mathrm{~K}$. Inset: Fig. 10 for low field region.

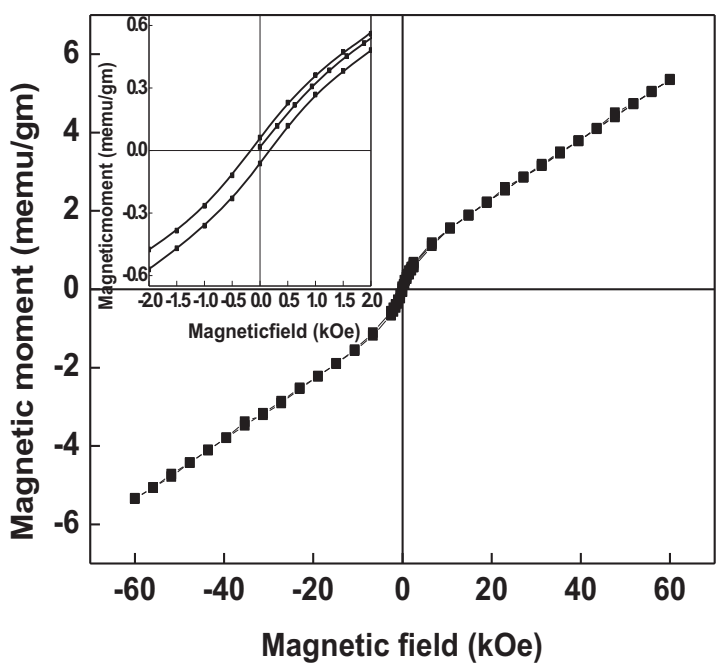

- Published by NRC Research Press 
in the material that may be due to structural distortion and $\mathrm{Fe}^{3+}$ ion distribution. An appearance of loop may be due to canting of anti-ferromagnetically ordered $\mathrm{Fe}-\mathrm{O}-\mathrm{Fe}$ chain of spins. The change in bond angle of $\mathrm{Fe}-\mathrm{O}-\mathrm{Fe}$ may be due to distortion created by $\mathrm{K}^{+}$and $\mathrm{Nb}^{5+}$ substitution. Saturated hysteresis loops are not observed even at a magnetic field of $60 \mathrm{kOe}$. The remnant magnetization is 0.0719 $\mathrm{emu} / \mathrm{gm}$ and coercive field is found to be $0.171 \mathrm{kOe}$.

\section{Conclusion}

Using a high-temperature solid-state reaction technique we have synthesized a single-phase BKFN in rhombohedra crystal system at room temperature. The ferroelectric studies at room temperature showed a hysteresis loop with remnant polarization $\left(2 P_{\mathrm{r}}\right)$ of $17.76 \mu \mathrm{C} / \mathrm{cm}^{2}$ and coercive field $\left(2 E_{\mathrm{c}}\right)$ of $36.58 \mathrm{kV} / \mathrm{cm}$. The detailed studies of frequency dependence of impedance spectroscopy suggested temperature-dependent relaxation phenomena in the material. Impedance spectra also indicate that the conduction contribution is mainly due to bulk in the low-temperature region (up to $380{ }^{\circ} \mathrm{C}$ ) and grain boundary effects above $380{ }^{\circ} \mathrm{C}$. The activation energy $(1.57 \mathrm{eV})$ estimated from grain boundary condition plot suggests the possibility of electrical conduction due to mobility of oxide ion vacancies at high temperatures. The frequency dependence of AC conductivity is found to obey Jonscher's universal power law. A very weak ferromagnetism is observed in the sample.

\section{Acknowledgements}

Authors are grateful to I.I.T. Kharagpur and Utkal University for some experimental help.

\section{References}

1. M. Kumar and K.L. Yadav. Appl. Phys. Lett. 91, 242901 (2007). doi:10.1063/1. 2816118.

2. S.R. Shannigrahi, A. Huang, D. Tripathy, and A.O. Adeyeye. J. Magn. Magn. Mater. 320, 2215 (2008). doi:10.1016/j.jmmm.2008.04.119.

3. X. Zheng, Q. Xu, Z. Wen, X. Lang, D. Wu, T. Qiu, and M.X. Xu. J. Alloys Compd. 499, 108 (2010). doi:10.1016/j.jallcom.2010.03.131.

4. V.A. Khomchenko, D.A. Kiselev, E.K. Selezneva, J.M. Vieira, A.M.L. Lopes, Y.G. Pogorelov, J.P. Araujo, and A.L. Kholkin. Mater. Lett. 62, 1927 (2008). doi:10.1016/j.matlet.2007.10.044.

5. J. Dhahri, M. Boudard, S. Zemni, H. Roussel, and M. Oumezzine. J. Sol. State Chem. 181, 802 (2008). doi:10.1016/j.jssc.2008.01.024.

6. G.A. Smolenskii and I. Chupis. Sov. Phys. Usp. 25, 475 (1982). doi:10.1070/ PU1982v025n07ABEH004570.

7. F. Kubel and H. Schmid. J. Cryst. Growth, 129, 515 (1993). doi:10.1016/00220248(93)90485-F.

8. F. Kubel and H. Schmid. Acta Crystallogr. B: Struct. Sci. 46, 698 (1990). doi: $10.1107 /$ S0108768190006887.
9. I.G. Ismailzade. Phys. Status Solidi B, 46, K39 (1971). doi:10.1002/pssb. 2220460156.

10. J. Wu and J. Wang. J. Appl. Phys. 105, 124107 (2009). doi:10.1063/1.3153955.

11. T. Kanai, S. Ohkoshi, A. Nagarjima, T. Watanabe, and K. Hashimoto Adv. Mater. 13, 487 (2001). doi:10.1002/1521-4095(200104)13:7<487::AIDADMA487>3.0.CO;2-L.

12. V.R. Palkar, K.G. Kumara, and S.K. Malik. Appl. Phys. Lett. 84, 2856 (2004). doi:10.1063/1.1695204

13. G.L. Yuan, S.W. Or, J.M. Liu, and Z.G. Liu. Appl. Phys. Lett. 89, 052905 (2006). doi:10.1063/1.2266992.

14. K.S. Nalwa, A. Garg, and A. Upadhyaya. Mater. Lett. 62, 878 (2008). doi:10. 1016/j.matlet.2007.07.002

15. P. Uniyal and K.L. Yadav. Mater. Lett. 62, 2858 (2008). doi:10.1016/j.matlet. 2008.01.103.

16. M.B. Bellakki and V. Manivannan. J. Sol-Gel Sci. Technol. 53, 184 (2010). doi:10.1007/s10971-009-2076-1.

17. H. Singh, A. Kumar, and K.L. Yadav. Mater. Sci. Eng., B, 176, 540 (2011). doi:10.1016/j.mseb.2011.01.010.

18. W.-M. Zhu, L.-W. Su, Z.-G. Ye, and W. Ren. Eur. Phys. J. B, 71, 377 (2009). doi:10.1140/epjb/e2009-00252-x.

19. Z.M. Tian, Y.S. Zhang, S.L. Yuan, M.S. Wu, C.H. Wang, Z.Z. Ma, S.X. Huo, and H.N. Duan. Mater. Sci. Eng., B, 177, 74 (2012). doi:10.1016/j.mseb.2011.07.012.

20. Y. Ma and X.M. Chen. J. Appl. Phys. 105, 054107 (2009). doi:10.1063/1.3081648.

21. Y. Nakashima, T. Shimura, W. Sakamoto, and T. Yogo. Ferroelectrics, 356, 180 (2007). doi:10.1080/00150190701512151.

22. S. Dash, R. Padhee, P.R. Das, and R.N.P. Choudhary. Phase Transitions, 87, 223 (2014). doi:10.1080/01411594.2013.812214.

23. P. Günter. J. Appl. Phys. 48, 3475 (1977). doi:10.1063/1.324196.

24. E. Wu. J. Appl. Crystallogr. 22, 506 (1989). doi:10.1107/S0021889889005066.

25. H.P. Klug and L.B. Alexander. X-Ray diffraction procedure. Wiley, New York 1974. pp. 687.

26. Y.K. Jun, W.T. Moon, C.M. Chang, H.S. Kim, H.S. Ryu, J.W. Kim, K.H. Kim, and S.H. Hong. Solid State Commun. 135, 133 (2005). doi:10.1016/j.ssc.2005.03. 038.

27. M.K. Kumar and S. Ramaprabhu. J. Alloys Compd. 453, 121 (2008). doi:10.1016/ j.jallcom.2006.11.060.

28. K. Kumari, K. Prasad, and R.N.P. Choudhary. J. Alloys Compd. 453, 325 (2008). doi:10.1016/j.jallcom.2006.11.081.

29. Y. Hosono, K. Harada, and Y. Yamashita. Jpn. J. Appl. Phys. 40, 5722 (2001). doi:10.1143/JJAP.40.5722.

30. A.K. Jonscher. Nature, 267, 673 (1977). doi:10.1038/267673a0.

31. K.S. Rao, D.M. Prasad, P.M. Krishnal, and J.H. Lee. Eur. Phys. J. Appl. Phys. 41, 229 (2008). doi:10.1051/epjap:2008026.

32. D.C. Sinclair and A.R. West. J. Mater. Sci. 29, 6061 (1994). doi:10.1007| BF00354542.

33. S. Sen, R.N.P. Choudhary, and P. Pramanik. Phys. B (Amsterdam, Neth.), 387, 56 (2007). doi:10.1016/j.physb.2006.03.028.

34. B. Behera, P. Nayak, and R.N.P. Choudhary. J. Alloys. Compd. 436, 226 (2007). doi:10.1016/j.jallcom.2006.07.028.

35. N. Ortega, A. Kumar, P. Bhattacharya, S.B. Majumder, and R.S. Katiyar. Phys. Rev. B, 77, 014111 (2008). doi:10.1103/PhysRevB.77.014111.

36. E.J. Abram, D.C. Sinclair, and A.R. West. J. Electroceram. 10, 165 (2003). doi:10.1023/B:JECR.0000011215.56084.87.

37. K. Funke. Prog. Solid State Chem. 22, 111 (1993). doi:10.1016/0079-6786(93) 90002-9.

38. R. Rai, S.K. Mishra, N.K. Singh, S. Sharma, and A.L. Kholkin. Curr. Appl. Phys. 11, 508 (2011). doi:10.1016/j.cap.2010.09.003 